\title{
Terapia Celular para Acidente Vascular Cerebral Isquêmico: Esperança ou Panacéia?
}

\author{
Stem Cells for Ischemic Stroke: Hope or Panacea?
}

Hans Fernando Rocha Dohmann e Jamary Oliveira Filho

Hospital Pró-Cardíaco, Universidade Federal do Rio de Janeiro e Instituto do

Milênio de Bioengenharia Tecidual - Rio de Janeiro - RJ

Células-tronco são definidas como células que mantêm a capacidade de auto-replicação e diferenciação em múltiplas linhagens ${ }^{1}$. Estas células, presentes em proporções variáveis em órgãos adultos, teoricamente podem dar origem a qualquer tecido vivo de um organismo. Embora o conceito de transplante de célulastronco não seja novo, vem tendo um interesse crescente com este tipo de terapia, após a demonstração de que a medula óssea adulta poderia fornecer uma quantidade suficiente de células multipotentes para um transplante autólogo ${ }^{2}$. Entretanto, o otimismo relacionado a qualquer novo tratamento deve ser avaliado com cautela.

Na edição de janeiro/06 dos Arquivos Brasileiros de Cardiologia (Vol. 86, págs. 52-55), Mendonça e cols. relataram o primeiro transplante autólogo de célulastronco derivadas da medula óssea em paciente com acidente vascular cerebral (AVC) isquêmico. Apesar dos resultados parecerem sugerir que o procedimento tenha sido seguro, exeqüível e resultado em um aumento precoce do metabolismo na região cerebral afetada pela isquemia, o simples relato de caso não deve receber um título que defina estes atributos. Portanto, tais termos devem ser suprimidos do título, o que já foi feito na versão eletrônica dos Arquivos Brasileiros de Cardiologia. Ainda mais quando sabemos que a análise da fase aguda do AVC isquêmico é um desafio e os autores corretamente enfatizaram que os achados nesta paciente podem ser secundários à recuperação espontânea. Em uma série de casos local, por exemplo, $61 \%$ dos pacientes apresentaram recuperação espontânea para independência completa (medida pelo escore de Rankin $<3)^{3}$. Além disso, nesse relato de caso, houve recanalização espontânea da artéria cerebral média, evidenciado pelo Doppler transcraniano, o qual é um preditor de bom prognóstico ${ }^{4,5}$.

Exames de neuroimagem para avaliação da evolução do AVC nesta paciente também foram realizados e incluíram ressonância magnética, cintilografia (SPECT) e tomografia computadorizada com emissão de pósitrons (PET) cerebral. Tais imagens também devem ser interpretadas no contexto da evolução natural do AVC isquêmico agudo. $\mathrm{O}$ padrão mais freqüente em pacientes com AVC agudo é que a área de necrose (core) é envolvida por uma área de hipoperfusão de tecido cerebral isquêmico, mas ainda viável (penumbra) ${ }^{6}$. Este padrão normalmente persiste por $24 \mathrm{~h}$. As células localizadas na zona de penumbra morrem progressivamente e o core se expande em aproximadamente, toda a área de hipoperfusão inicial ${ }^{6}$. A melhora da hipoperfusão inicial é esperada na maioria dos pacientes com AVC com o decorrer do tempo, e até as anormalidades observadas nas imagens de difusão podem apresentar melhora em casos selecionados ${ }^{7,8}$. 0 aumento do metabolismo regional neste caso foi sugerido pelo PET, mas alguma regeneração tecidual espontânea é possível em pacientes com AVC. A falta de dados quantitativos limita as conclusões quanto a este achado.

A pesquisa com células-tronco abre uma avenida fascinante em doenças neurológicas. Entretanto muito ainda precisa ser esclarecido: estudos de ciência básica devem elucidar os mecanismos exatos pelos quais a terapia celular é capaz de recuperar déficits relacionados ao AVC; estudos clínicos em seres humanos, controlados e randomizados serão necessários para avaliação dos pacientes submetidos ao transplantes com células-tronco da medula óssea comparados àqueles com história natural do AVC isquêmico. A avaliação cuidadosa da segurança deste tipo de procedimento também é fundamental, uma vez que um risco aumentado de trombose no sítio de injeção e desenvolvimento de focos epileptogênicos são ainda uma preocupação à medida que mais pacientes são estudados. Os autores do estudo mencionado devem ser parabenizados tanto pela experiência pioneira quanto pelos comentários realísticos, sendo que os resultados comparativos da fase I são ansiosamente esperados. A terapia celular provavelmente não será uma panacéia para o tratamento de doenças neurológicas, mas a esperança do sucesso deve estimular a continuidade da pesquisa científica nesta área. Nossos pacientes merecem isso. 


\section{REFERÊNCIAS}

1. Körbling M, Estrov Z. Adult stem cells for tissue repair - a new therapeutic concept? N Engl J Med. 2003;349:570-82.

2. Jiang $Y$, Jahagirdar BN, Reinhardt RL et al. Pluripotency of mesenchymal stem cells derived from adult marrow. Nature. 2002;418:41-9.

3. Oliveira-Filho J, Silva SCS, Trabuco CC et al. Detrimental effect of blood pressure reduction in the first 24 hours of acute stroke onset. Neurology. 2003;61:1047-51.

4. Baracchini C, Manara R, Ermani M, Meneghetti G. The quest for early predictors of stroke evolution. Can TCD be a guiding light? Stroke. 2000;31:2942-7.

5. Alexandrov AV, Felberg RA, Demchuk AM et al. Deterioration following spontaneous improvement: Sonographic findings in patients with acutely resolving symptoms of cerebral ischemia. Stroke. 2000;31:915-9.

6. Schwamm LH, Koroshetz WJ, Sorensen AG et al. Time course of lesion development in patients with acute stroke. Serial diffusionand hemodynamic-weighted magnetic resonance imaging. Stroke. 1998;29:2268-76

7. Lecouvet FE, Duprez TPJ, Raymackers JM, Peeters A, Cosnard G Resolution of early diffusion-weighted and FLAIR MRI abnormalities in a patient with TIA. Neurology. 1999; 52:1085-7.

8. Krueger K, Kugel H, Grond M, Thiel A, Maintz D, Lackner K. Late resolution of diffusion-weighted $M R I$ changes in a patient with prolonged reversible ischemic neurological deficit after thrombolytic therapy. Stroke. 2000;31:2715-8. 